\title{
Contextos
}

\section{Comuna 13, estudio de caso: la historia relatada en las paredes como estrategia de un emprendimiento social}

\author{
Comuna 13, case study: the story told on the walls as a strategy for a social entrepreneurship
}

\author{
Flor Adriana Pedraza-Pacheco \\ Universidad Católica de Colombia. Bogotá (Colombia) \\ Facultad de Diseño, Programa de Arquitectura \\ Andrés Rodrigo Santana-Murcia \\ Universidad Católica de Colombia. Bogotá (Colombia) \\ Programa de Economía
}

Pedraza-Pacheco, F. A., \& Santana-Murcia, A. R. (202I). Comuna I3 estudio de caso: La historia relatada en las paredes como estrategia de emprendimiento social. Revista de Arquitectura (Bogotá), 23(2), 3-II. https://doi. org/l0.14718/RevArq.2021.4102

\author{
Flor Adriana Pedraza-Pacheco \\ Arquitecta, Pontificia Universidad Javeriana. Bogotá, D. C. \\ Maestranda en Ciencias de la Educación y Procesos Cognitivos, Uni- \\ versidad de Cuauhtémoc, Aguascalientes, México. \\ Docente de tiempo completo, Programa de Arquitectura, Facultad de \\ Diseño, Universidad Católica de Colombia. \\ https://scholar.google.com/citations?hl=es\&user=2sns7GUAAAA \\ (D) https://orcid.org/0000-0002-8073-0278 \\ (19) fapedraza@ucatolica.edu.co \\ Andrés Rodrigo Santana-Murcia \\ Administrador de Empresas, Universidad Nacional de Colombia, Bo- \\ gotá, D. C. \\ Especialista en Gerencia de Recursos Humanos Universidad Sergio \\ Arboleda, Bogotá, D. C. \\ Magíster en Administración, Universidad Nacional de Colombia, Bo- \\ gotá, D. C. \\ Doctorando en Ciencias Económicas, Universidad Nacional de \\ Colombia, Bogotá, D. C. \\ Docente de tiempo completo, Programa de Economía, Universidad \\ Católica de Colombia. \\ https://scholar.google.es/citations?user=9Mp4x7gAAAAJ\&hl=es \\ (1) https://orcid.org/0000-0002-4566-9280 \\ (10) arsantana@ucatolica.edu.co
}

\section{Resumen}

El estudio de caso ha demostrado ser una herramienta metodológica adecuada para la investigación científica en diferentes áreas del conocimiento, dada su facilidad para obtener información desde fuentes cualitativas y cuantitativas. El artículo presenta el trabajo adelantado por los semilleros de investigación Pedagogía del Diseño, y Patrimonio Cultural, de la Facultad de Diseño de la Universidad Católica de Colombia, a lo largo de 2018, 2019 y 2020, en la ciudad de Medellín, Antioquia. La investigación dio inicio con la identificación de lo que significa para la comunidad barrial de la Comuna I 3 el patrimonio cultural, material e inmaterial, a partir del análisis de eventos patrimoniales no reconocidos y su contrastación con las variables descriptivas definidas por United Nations Educational, Scientific and Cultural Organization (UNESCO) (2003). En este orden de ideas, se seleccionó el Tour del Grafiti como evento patrimonial no reconocido. Su análisis parte del reconocimiento comunitario del grafiti como expresión artística y la importancia del tour como proyecto de emprendimiento social de la zona.

Palabras clave: Aprendizaje activo; construcción comunitaria; emprendimiento social, identidad cultural, patrimonio cultural; transposición didáctica

\begin{abstract}
The case study has proven to be an adequate methodological tool for scientific research in different areas of knowledge, given its ease to obtain information from qualitative and quantitative sources. The article presents the work carried out by the "Design Pedagogy" and "Cultural Heritage" research "seedbeds" of the Faculty of Design of the Universidad Católica de Colombia throughout the years 2018, 2019 and 2020 in the city of Medellín, Antioquia. The research began by identifying the meaning that the cultural, tangible and intangible heritage has for the neighborhood community of commune 13 , from the analysis of unrecognized heritage events and their contrast with the descriptive variables defined by UNESCO 2003. In this order of ideas, the "GraffitiTour" was selected as an unrecognized heritage event. Its analysis is based on the community recognition of graffiti as an artistic expression and the importance of the tour as a project of social entrepreneurship project in the area.
\end{abstract}

Keywords: Active learning; community construction; social entrepreneurship, cultural identity, cultural heritage; didactic transposition

\section{Introducción}

Desde hace décadas, en los contextos nacionales e internacionales se ha conferido una gran responsabilidad a los programas de educación superior. El apartado "Educación para las Américas", del Foro Mundial sobre la Educación, de la UNESCO, celebrado en el 2000 bajo el Marco de Acción Dakar, hace hincapié en el papel de la educación superior como pilar para el mejoramiento de los aspectos cualitativos y productivos en los diferentes programas educativos, lo que posiciona a las Instituciones de educación superior como entidades responsables de reflexionar y apoyar el perfeccionamiento de las competencias laborales y ocupacionales requeridas por el entorno social actual.

Con el compromiso de promover el interés de los estudiantes en la investigación, la Revista de Arquitectura (Bogotá) considera fundamental ser el andamiaje para exponer temas que se desarrollan en los semilleros de investigación, tal como en los semilleros titulados Pedagogía del Diseño, y Patrimonio cultural, que son la plataforma abierta para el desarrollo y promoción del debate a temáticas como la construcción de los imaginarios urbanos contemporáneos y sus nuevos alcances de colectividad. Se expone el estudio de caso rea- 
lizado por los semilleros durante 2018, 2019 y 2020, enfocados en el reconocimiento base de las características del patrimonio cultural y la identificación de este en un territorio específico. Dicha reflexión llevó a plantear el desarrollo de posibles herramientas pedagógicas significativas que cumplieran con el fin de establecer cómo a través de un evento cultural artístico reconocido en una comunidad se pueden fomentar fines concretos de identidad y sentido de pertenencia de territorio, tanto para la comunidad académica como para la comunidad barrial, fortaleciendo a los estudiantes como posibles formadores de formadores, y a la comunidad, como la entidad promotora del desarrollo en cocreación de herramientas, estrategias y metodologías de aprendizaje activo y empoderamiento realizando la caracterización de una promesa de valor en un posible y futuro proyecto de emprendimiento social.

Dicho estudio da inicio con el entendimiento y la identificación de lo que es en una comunidad barrial el patrimonio cultural material e inmaterial identificando estudios de caso de eventos patrimoniales no reconocidos (desde las definiciones formales) y diferentes variables descriptivas de qué es el patrimonio cultural y qué es tal cosa en una comunidad, para determinar así cómo se asimilan o se adquieren cognoscitivamente habilidades, prácticas y costumbres que se definan como únicas y autóctonas en el tiempo "caracterización de la definición de patrimonio", y que, si bien estarían enmarcadas en dicha descripción por la UNESCO en la Convención del Patrimonio Mundial, en 1975, y consolidadas en 2003 — donde se afirma que "El Patrimonio Cultural son los usos, representaciones, expresiones, conocimientos, saberes y técnicas, junto con la elaboración y tradición de objetos y espacios culturales que les son inherentes a las comunidades, los grupos y en algunos casos los individuos reconozcan como parte integrante de su patrimonio cultural" (Convención para la Salvaguardia del Patrimonio Cultural Inmaterial UNESCO 2003)_, no pierden el valor intrínseco si no son reconocidas según tal definición; pero sí son reconocimientos culturales, que podrían ser el pilar para la creación de proyectos que integran las funciones de la academia y el trabajo colaborativo con comunidades complejizando alternativas por medio del modelo Business Model Canvas, o lienzo del modelo del negocio, para potencializar soluciones de problemas barriales y proyectos de emprendimiento e innovación en las comunidades.

Es así que como estudio de caso se seleccionó a la Comuna 13, y su Tour del Grafiti en la ciudad de Medellín, Antioquia, donde se analizó cómo se redefine el patrimonio cultural iniciando desde el reconocimiento comunitario de una actividad particular: el grafiti, que no es considerado un evento patrimonial cultural por sí mismo, y que, además, no está dentro de los estándares y los propósitos de la construcción de ciudad contemporánea, pero que como fenómeno cultural logra resignificarse en este contexto específico para ser soporte de apoyo en el desarrollo del emprendimiento social de este sector de la ciudad de Medellín. Este caso particular de estudio se pone de manifiesto como el ejemplo del cómo el saber sabio y el saber popular, a través de la "Transposición Didáctica-Saber Sabio al Saber Enseñado" (Chevellard Yves, 1998, citado por Mora Castiblanco, 2014, p. 97), articula y proyecta todo un sector "Proyección que trata de replantear cuidadosamente las transformaciones que puede sufrir un saber para que sea enseñado; es decir, trata de articular el análisis epistemológico con el análisis didáctico". (Ramírez Bravo, 2005, p. 34); es decir, sin la intencionalidad del raciocinio de un ejercicio formulado desde una organización, pero considerando que las dinámicas planteadas en la Comuna 13 logran ser un ejemplo claro de la realización de un proyecto de emprendimiento social, creado con el ánimo de preservar las expresiones culturales urbanas, al tiempo que favorece la generación de ingresos en la comunidad, promueve el desarrollo económico local y brinda un reconocimiento a la memoria histórica de los pobladores. Agregando a esto, es un ejemplo claro de un fenómeno cultural de características que son debatidas actualmente en la nueva significación urbana por el derecho mismo a poseer y pertenecer a la ciudad: "El graffiti es algo que invade nuestras ciudades, algo que estamos obligados a consumir puesto que aparece en los trenes y fachadas por las que pasamos habitualmente y son marcas, colores, ideas y mensajes que nosotros no hemos pedido y que forman parte de nuestra sociedad desde principios de los años ochenta" (Reyes Sánchez, 2012, p. 53), y la cual, en el imaginario colectivo, está planteada desde la planeación normativa, trasciende dicha discusión y se convierte en el puente para pertenecer a la estructura de la ciudad, sin importar normas urbanas o declaratorias culturales.

\section{Metodología}

Para realizar el ejercicio de analizar, comprender y proponer herramientas pedagógicas de aprendizaje significativo del patrimonio cultural a través de la transposición didáctica, y con el fin de realizar la identificación por parte de las comunidades -académica y comunidad de barrio- de los posibles elementos caracterizados como patrimonio cultural, que posteriormente puedan ser la plataforma de base para un desarrollo colectivo de un proyecto de emprendimiento comunitario, se realizó el estudio de caso, elaborado en tres fases inductivas que permitieran posteriormente flexibilizar los resultados de las herramientas según los indicadores obtenidos: 


\section{Fase 1: análisis de estudio de caso: intervenciones pictóricas de la Comuna 13 San Javier}

"El tour de la subcultura" posterior a un reconocimiento de la actividad del grafiti como un evento urbano contemporáneo, se compiló, y sus registros fueron revisados, con una base de datos en diversas ciudades que incluyera: mapeo histórico, libros, artículos científicos y periodísticos, así como entrevistas, que dieran información sobre cómo fue la conformación de la Comuna 13 San Javier, estudiando el porqué de su origen hasta el desarrollo de la actividad en cuestión. Esta búsqueda permitió interpretar una actividad no reconocida como patrimonio en el lugar de estudio y elaborar un marco conceptual del contexto con los posibles puntos relevantes que convirtieron la práctica en el vínculo de desarrollo articulador, junto con otros emprendimientos a una floreciente economía del turismo barrial que actualmente genera importantes recursos en la Comuna 13 San Javier. Tal como lo evidencia el artículo periodístico del Toronto Star,

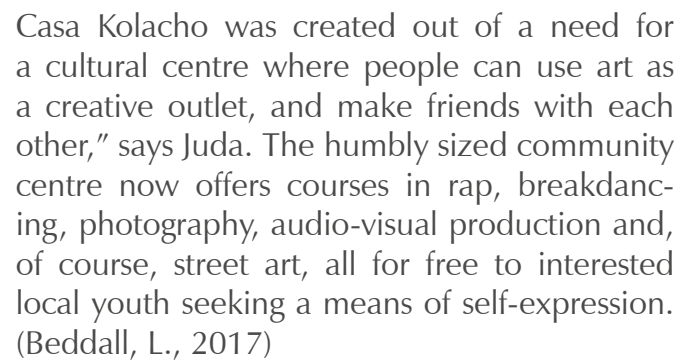

El Tour del Grafiti de la Comuna 13 pone de manifiesto que este se efectuó en función de una caracterización específica que dio las pautas y las bases para la construcción del marco de desarrollo barrial, y permitió, además, verificar que estas intervenciones cumplían con los indicadores que determinan el hecho cultural como patrimonio cultural de resignificación gestionando, por parte de su propia comunidad, una declaratoria de protección y salvaguardia, sin necesidad de ser determinada y titularizada por entes estatales o académicos. El ejercicio proporcionó acceso a profundizar e indagar más allá de juicios de valor estéticos y aproximarse a la conciencia de la incidencia del evento en la transformación urbano paisajística, y dando pie la formulación de evidencias de consideración por medio de las cuales podría legitimarse el arte urbano, en este caso particular, por trascender como un símbolo de una comunidad y construir cambios significativos sociales, culturales y de aprehensión desde la participación de una colectividad a emprendimientos tangibles y perdurables en el tiempo.

El recorrido Tour del Grafiti de la Comuna 13 también pone de manifiesto que este se efectuó en función de una caracterización específica que dio las pautas y las bases para la construcción del marco conceptual, permitiendo verificar si estas intervenciones cumplían con los indicadores que determinan el hecho cultural como patrimonio cultural.

\section{Fase 2: elaboración de herramientas metodológicas desde la transposición didáctica para la identificación del patrimonio cultural no reconocido}

A partir del estudio y el análisis del referente, el grupo del semillero de Patrimonio logró interiorizar un significado del saber teórico del patrimonio cultural, y cómo este podría desligarse de la teorización misma de la significación académica para analizar, estudiar y validar los diversos significados culturales en los contextos comunitarios. Fue así como, partiendo de esta información del Tour del Grafiti en la Comuna 13, se reconoció que dicha herramienta debe ser enmarcada desde la construcción de conocimiento significativo en el saber popular al saber académico, y permitir posteriormente dinámicas de la transposición didáctica de ambos saberes. Como objetivos principales de la herramienta se determina que esta debe tener las siguientes características:

1. Definición y significación de la interculturalidad entre academia y comunidad (específico y medible).

2. Formación a jóvenes formadores para el fomento y la preservación del patrimonio cultural material e inmaterial en comunidades barriales (alcanzable y retador).

3. Diseño de una herramienta pedagógica para el aprendizaje significativo en el reconocimiento del patrimonio cultural a partir de imágenes (tiempo).

\section{Fase 3: construcción de un modelo de emprendimiento social: el Business Model Canvas}

El tour del grafiti surge como una iniciativa articuladora de las expresiones artísticas de los grafiteros de la Comuna 13, en un esfuerzo por visibilizar las manifestaciones culturales generadas por los pobladores como respuesta a una serie de acontecimientos violentos que, como

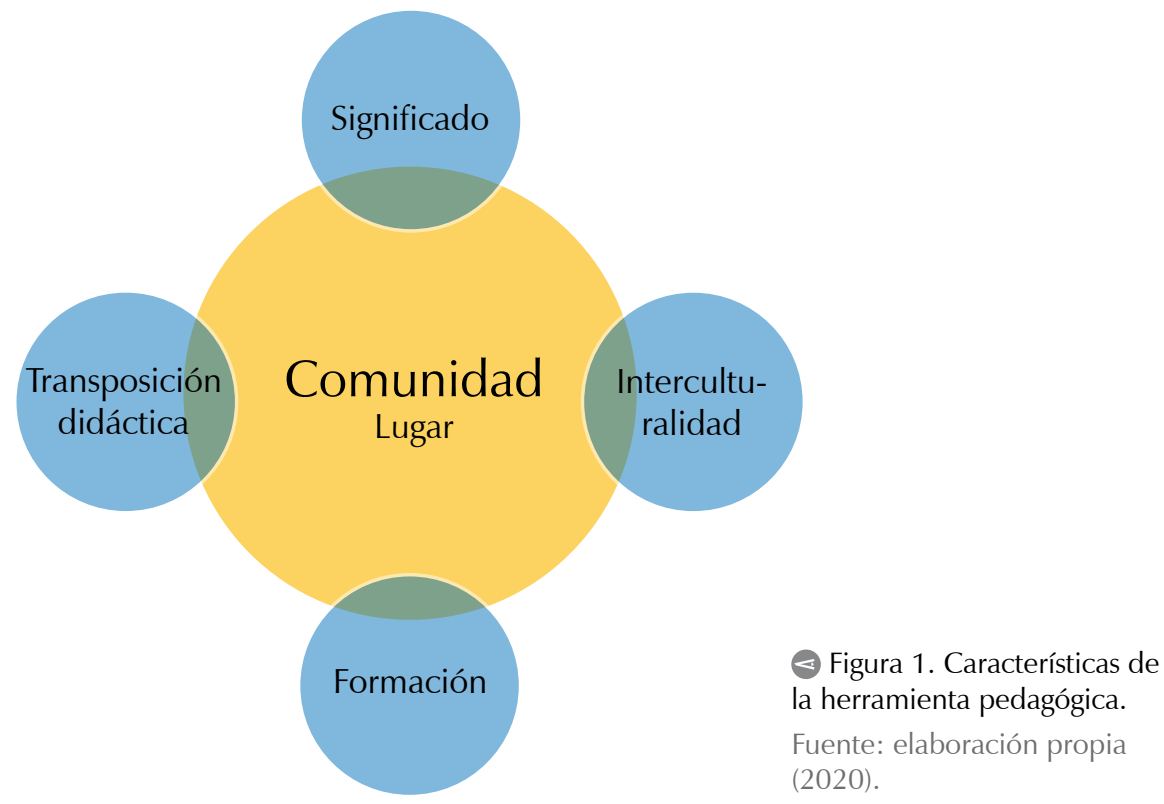


comunidad, han venido afrontando desde hace décadas.

Tal iniciativa pudo ser analizada desde la lógica del emprendimiento social, toda vez que nace en el seno de la sociedad urbana de Medellín, con el objeto de contribuir a dar solución a una serie de problemáticas sociales (Vázquez Parra, 2018) que incluyen la violencia, la pobreza, el desempleo y la desigualdad.

El Business Model Canvas (Osterwalder \& Pigneur, 2011, p. 15) permitió comprender la naturaleza de los modelos de negocio, tras presentar, en un formato sencillo, de nueve cuadrantes, los aspectos básicos para la generación de valor. En un contexto en el que la generación de valor social se enmarca en el emprendimiento, el Business Model Canvas se convierte en una alternativa apropiada para el análisis.

La construcción de los nueve cuadrantes para el tour del grafiti siguió esta metodología. Con ella fue posible identificar la propuesta de valor, los aliados clave, los recursos clave y todos los aspectos que hacen de esta iniciativa una apuesta viable para la superación de las problemáticas sociales que agobian a la Comuna 13. La desagregación completa del modelo de negocio se presenta de manera detallada, como insumo para la comprensión de la dinámica de un caso de emprendimiento social de alto impacto en Colombia.

\section{Resultados}

\section{Validación del lugar como posible patrimonio cultural Comuna 13 San Javier, de Medellín}

Sin duda alguna, la ciudad de Medellín, en Colombia, es actualmente símbolo de la reivindicación del contexto de violencia vivido en las décadas de 1980 y 1990, y se ha convertido en los últimos 30 años en un destino turístico de gran relevancia para la economía del departamento y del mismo país: es la tercera ciudad más visitada por el turismo extranjero y nacional, según cifras del Ministerio de Comercio, Industria y Turismo (MinCIT, 2018). Dicho progreso y esa imagen de innovación convergen en los programas de desarrollo y de las diversas intervenciones urbano-arquitectónicas a las que los entes gubernamentales, junto con las empresas públicas y privadas, les han apostado en los 20 años anteriores, lo que ha detonado un evidente empoderamiento por parte del Estado, con el desarrollo de proyectos viales, parques, bibliotecas y edificaciones estatales que, sin duda alguna, benefician al grueso de la población, sin distinción social. Cabe destacar que estas intervenciones han generado un gran impacto a la ciudad y a la comunidad en general; sin embargo, cuando se profundiza en dichos cambios, debe destacarse la participación activa de las diferentes comu- nidades que intervienen como entes aportantes y detonantes, y así posibilitan los cambios de estas intervenciones estatales y construyen estrategias de empoderamiento para beneficio y bienestar de la colectividad.

Este es el caso de la reconocida Comuna 13 San Javier, ubicada en la zona centro-occidente de la ciudad, y conformada como un asentamiento de borde de caracterización subnormal que alberga una histórica invasión de migrantes campesinos víctimas del conflicto armado de diversas zonas limítrofes del departamento de Antioquia. Desde los años cuarenta del siglo XX hasta la primera década del siglo XXI, la zona fue transformada drásticamente en cuanto al número de habitantes del sector, para conformar en la actualidad una comuna de 21 barrios sectorizados de los estratos 1-3, según el tiempo de consolidación. Así pues, indagando en su conformación histórica, la población de la comuna aumentó notablemente en los decenios de 1940 y 1950, como antesala del recrudecimiento de la violencia del conflicto armado que vendría a desarrollarse formalmente en la década de 1960, y que en las dos décadas siguientes aumentó, como resultado de los desplazamientos forzados por la guerra interna que, sin tregua, sucedía en las zonas rurales del país. Las dinámicas de estas dos décadas (1980 y 1990) fueron el escenario donde el proceso de desarrollo y fortalecimiento de bandas delincuenciales, se enquistó en el sector, al conformarse grupos de milicianos de apoyo al narcotráfico, el paramilitarismo y la guerrilla. Esta realidad de violencia recrudeció por acciones del Estado unido a grupos paramilitares que, con el ánimo de dominio y control de la zona, tomaron posesión de esta, y dejaron la huella indeleble de desapariciones forzadas y falsos positivos en intervenciones como la Operación Mariscal y la Operación Orión, en 2002. Si bien se debe reconocer que estas situaciones de violencia en la actualidad han disminuido notablemente, existe aún la estela del conflicto local delincuencial, a la cual sus habitantes, en un trabajo de concientización, convivencia y participación, tratan de combatir luchando con proyectos sociales que empoderen y fortalezcan la comunidad.

Contextualizando estos eventos históricos con las manifestaciones pictóricas de los grafiteros de la comuna, es claro que el panorama descrito fue la inspiración para que se realizaran aleatoriamente intervenciones visuales, las cuales tenían la misma intención básica de los valores propios de la acción grafitera alrededor del mundo: marcar de manera tangible, pero efímera, un sector a través de la comunicación visual, pero no con una finalidad estético-urbana específica. $Y$ pese a que la carga histórica pueda ser el fundamento inspirador para la elaboración de estos grafitis, en el caso particular de la Comuna 13 se hace imperativo reconocer que el detonante de la manifestación actual fue en 2011, con la inauguración del proyecto de las escaleras eléctricas, que 
abrió paso al escenario para que los grafiteros plasmaran en las casas colindantes a los $384 \mathrm{~m}$ longitudinales sus intervenciones. Artistas como 'Jomag', 'Chota' y 'Yess', probablemente, dieron inicio con un mural que expresaba históricamente lo que se había vivido en la comuna y su contexto de violencia, o por lo menos así lo manifiesta en entrevista el guía turístico Andrés Mesa, del Tour del Grafiti de la Comuna 13:

El primer graffiti es un dato que nadie debe saber, porque en principio no se pensó escaleras como turismo, cuando se hizo la construcción llegaron muchachos a graffitear pero no como tal en el sentido del turismo, si vamos a hablar en ese tema yo me atrevería a decir que puede ser Jomag, Chota y Yess entre ellos tres porque fueron los que pintaron el primer muro que era el de abajo y que hoy ya no está. (Entrevista personal con Andrés Mesa, septiembre 19 de 2020)

Junto con las escaleras eléctricas, otro de los proyectos urbanos que sirvieron como lienzo para que los grafiteros de la zona continúen desplegando sus intervenciones artísticas fue la construcción del Viaducto Media Ladera, el cual buscó solucionar los problemas de conectividad y movilidad de los barrios Independencia I e Independencia II, que extiende la galería ya plasmada en el recorrido de las escaleras eléctricas.

En este panorama, y con la contextualización del significado de la acción grafitera en el lugar, se realizó el recorrido de la Comuna 13 teniendo como objetivo primordial constatar los siguientes indicadores de patrimonio cultural, dictaminados en las conferencias mundiales sobre las políticas culturales celebradas en México por la UNESCO (1982):

1. 23. El patrimonio cultural de un pueblo comprende las obras de sus artistas, arquitectos, músicos, escritores y sabios, así como las creaciones anónimas surgidas del alma popular.

2. 24. Todo pueblo tiene el derecho y el deber de defender y preservar su patrimonio cultural, ya que las sociedades se reconocen a sí mismas a través de los valores en que encuentran fuente de inspiración creadora.

En este orden de ideas, cabe destacar que el recorrido que se realiza en el tour es, por sí mismo, un fundamento histórico del origen de la comuna, y se convierte en una herramienta adicional para la comprensión de cómo se establecieron algunos de los barrios icónicos en el sector. Cabe destacar que la mayoría de los barrios de la Comuna 13 surgieron como procesos urbanos clandestinos, y que su ordenamiento urbanístico estuvo sujeto a una legitimización tardía por parte del Estado, debido a que fue muy posterior a la consolidación barrial, como es lo acostumbrado en asentamientos ilegales que desbordan los límites de la ciudad. Dejando claro el anterior punto, podemos proceder a la descripción del tour, el cual tuvo como punto de partida la estación de metro de San Javier, para posteriormente transitar por los barrios de Villa Laura, Independencia I e Independencia II, y el reco-

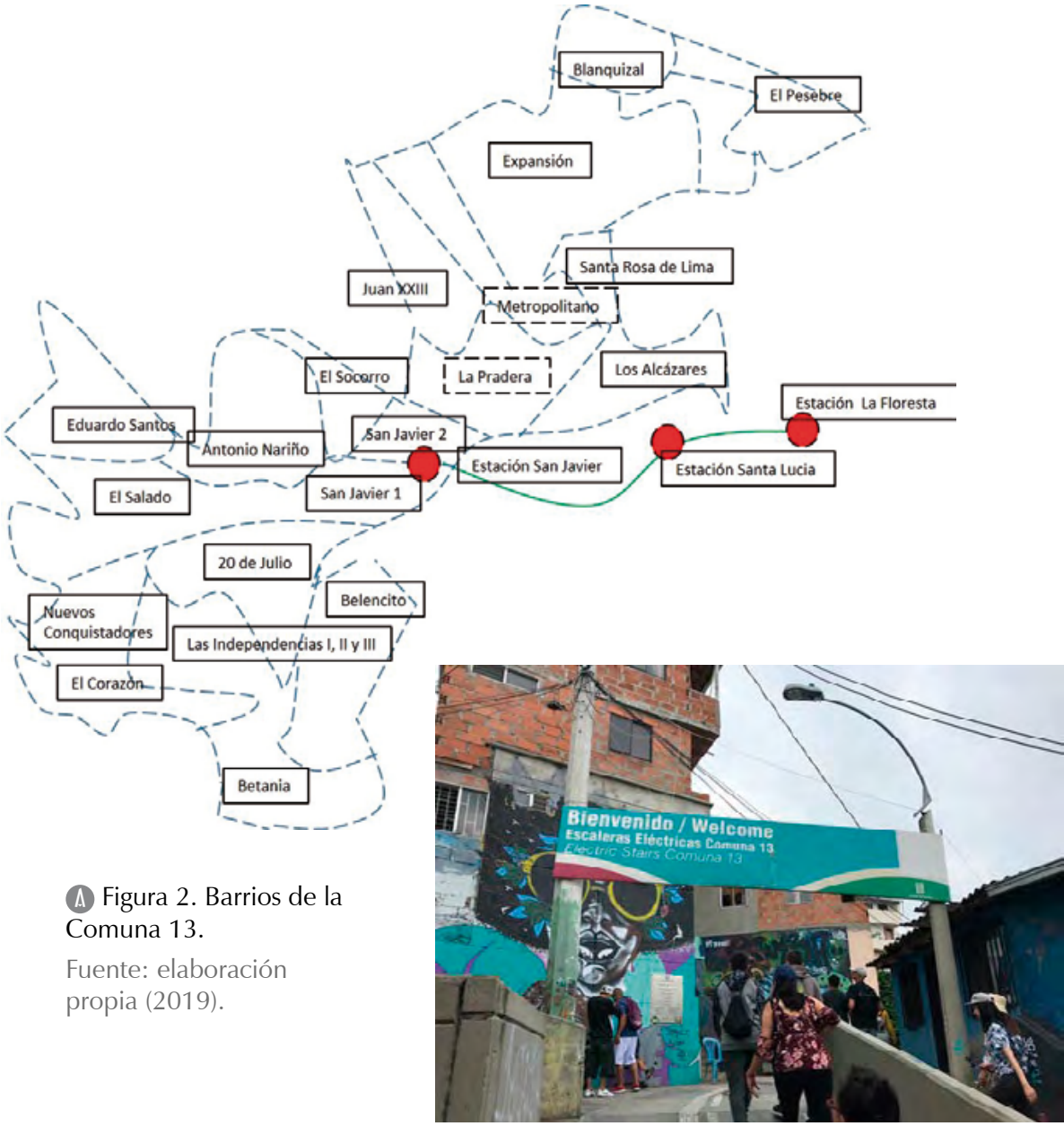

nocido barrio 20 de Julio, fundado en la década de 1970, como una extensión del barrio San Javier. Como un paréntesis del tour guiado, se consideró de vital importancia visitar el cementerio de la Comuna 13, ya que allí se encuentra otra muestra importante de grafitis realizados por la comunidad, y en los cuales se conmemora a algunas de las víctimas de la violencia a la que fue sometida desde sus orígenes la comuna. Estos murales se han desarrollado y consignado gracias al programa de talleres Arte para la Reconciliación, los cuales han sido una estrategia local que promueve las actividades culturales y fomenta el cambio social consciente, sostenible y permanente de la comunidad. En ruta nuevamente con el itinerario designado, se inició un inventario de los grafitis de la Comuna 13, donde no solo se encontraron los pictogramas descritos en los dos ejercicios de contextualización (Bubble Letters, Tags, Personajes y Murales), sino que se encontró un amplio despliegue de estilos y desarrollo de técnicas, las cuales son el componente que incorpora la peculiar estética de los barrios intervenidos y adiciona una estructura de carácter más artístico a la muestra. Y aunque los grafiteros más puristas podrían considerarlo un despropósito mismo respecto a su filosofía, es a partir del deseo y de la necesidad territorial por empoderarse como colectivo sobre su comuna como los grafiteros de la Comuna 13 reconsideran la expresión individual con el fin de generar alternativas que, como detonadores, posibiliten desarrollar nuevas formas de empoderamiento para que sus barrios superen su propia historia violenta sobrepasando los valores de contracultura propios de la práctica y convirtiéndose en el hito de salvamento para sus habitantes.
(A) Figura 3. Inicio del Tour del Grafiti Comuna 13: escaleras eléctricas.

Fuente: fotografía de José Fernando Salazar Serna (2019). 
Actualmente la producción de arte callejero como alternativa artística de innovación cultural en contextos urbanos, sean estos locales o globales, provoca y genera tensiones entre sus artífices (grafiteros y artistas de street art) con otros actores que forman parte de la escena de la ciudad, tales como la administración pública. A partir de estas dinámicas se va construyendo en simultáneo un espacio de tensiones y cercanías. (Klein, 2018, p. 57)

Es así como esta puesta en escena se reafirma para que la comunidad, de manera creativa, se incorpore a la iniciativa respaldando el recorrido con otro tipo de emprendimientos y dándole aún más valores de interés al recorrido. Emprendimientos como Casa Kolacho Centro Cultural, que promueve y gestiona la mayoría de los grafitis de la comuna, Café con aroma de Barrio y helados caseros como Cremas de Doña Consuelo, entre otros, se desarrollan en la actualidad como microempresas de gran importancia para la economía local emergente, y son, además, el pilar de la promoción del turismo cultural adoptado en la galería de cielos abiertos Comuna 13.

Los hallazgos muestran que puede considerarse que Casa Kolacho utiliza una estrategia de comunicación transmedia, que aunada a la participación ciudadana consigue la movilización social, además la producción cultural y creativa del colectivo involucra a los habitantes del barrio y representa su quehacer más allá de su arte, tiene repercusión en la identidad de la ciudad. (Rojas de Francisco \& Henao, 2017, p. 3)

\section{Modelo de emprendimiento social: el Business Model Canvas del Tour del Grafiti}

La caracterización del modelo de emprendimiento social desarrollado en la Comuna 13 se rige por el modelo de nueve cuadrantes, propuesto por Osterwalder y Pigneur (2011). En él se desagregan, de manera ordenada, las cuatro áreas principales de cualquier modelo de negocio: clientes, oferta, infraestructura y viabilidad económica (Osterwalder \& Pigneur, 2011, p. 15), las cuales dan respuesta a cuatro grandes interrogantes: ¿cómo? ¿Qué? ¿Quién? ¿Cuánto? (Carretto et al., 2013).

El lado derecho del lienzo (figura 4) presenta la forma como la empresa o el proyecto crean valor, en tanto que el lado izquierdo muestra los aspectos que determinan la eficiencia del modelo. La figura 4 presenta de manera resumida los nueve cuadrantes del modelo expuesto y la descripción de su naturaleza (Carretto et al., 2013).

El Business Model Canvas ha sido usado ampliamente en el campo de los negocios; también ha demostrado tener una gran utilidad para la modelación de organizaciones no lucrativas, instituciones benéficas y empresas sociales de carácter lucrativo (Montalvo-Castro, 2016, p.156).

La propuesta de valor, eje articulador de los nueve cuadrantes, puede ser adaptada a proyectos y empresas sin ánimo de lucro. Su propósito es "solucionar los problemas de los clientes y

\section{LIENZO DE MODELO DE NEGOCIO: NOMBRE DE LA EMPRESA}

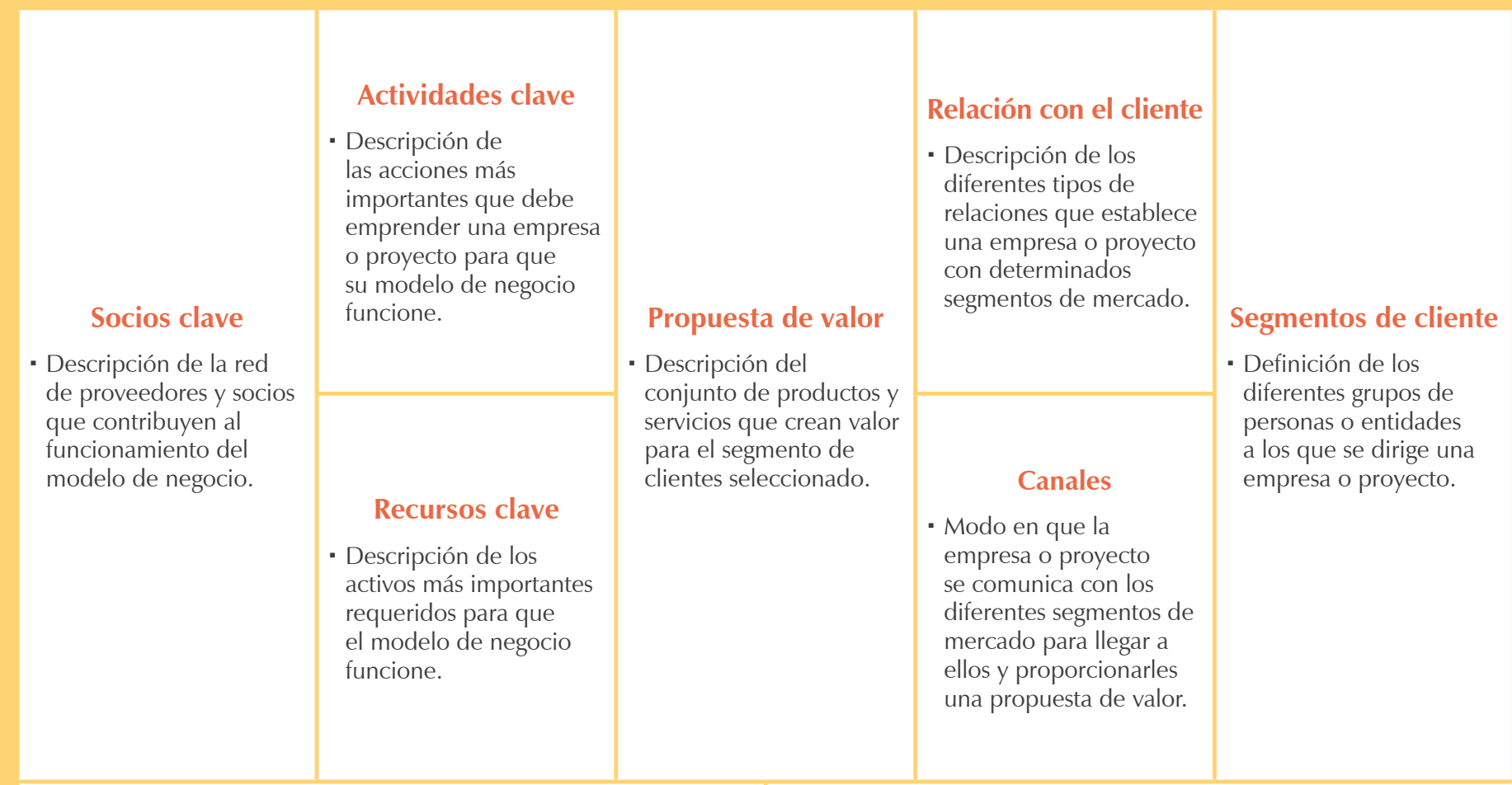

Estructura de costos

- Descripción de todos los costos que implica la puesta en marcha del modelo de negocio.

\section{Fuentes de ingresos}

- Flujo de caja que genera una empresa o proyecto en los diferentes segmentos de mercado que tiene. 
satisfacer sus necesidades" (Osterwalder \& Pigneur, 2011, p. 16) a través de la oferta de un "conjunto de productos y servicios que crean valor para un segmento de mercado específico" (Osterwalder \& Pigneur, 2011, p. 22).

Al trasladar estos principios a un proyecto de emprendimiento social, resulta claro que la promesa de valor debe dirigirse a solucionar uno o varios de los problemas de una comunidad específica, o a satisfacer sus necesidades, a través de la generación de bienes o servicios que cubran uno o varios segmentos.

A partir de allí es posible esbozar los demás elementos del modelo. Se parte de la identificación del conjunto de acciones, recursos, aliados y canales que hacen posible crear, proporcionar y captar valor (Osterwalder \& Pigneur, 2011, p. 16).

La propuesta de valor del Tour del Grafiti consiste en ofrecer una experiencia histórico-cultural, a través de la presentación de narrativas artísticas de los habitantes de la Comuna 13 (figura 5). Tal propuesta, dirigida a turistas nacionales e internacionales, se soporta en una serie de socios clave, que pueden resumirse en: artistas callejeros, administraciones públicas y emprendedores locales, quienes individualmente, pero de manera articulada, dirigen sus esfuerzos a crear y aportar valor

La generación de mayores ingresos para los emprendimientos locales viene determinada por dicha integración. Con ello no solamente se combate la pobreza de la Comuna 13, sino que, además, se promueve la cohesión social y se ofrecen alternativas de empleo a sus habitantes, al tiempo que se rescatan los valores históricos y culturales de una región azotada por la violencia.

\section{Discusión}

\section{Validación del estudio de caso Tour del Grafiti de la Comuna 13 como posible patrimonio cultural identificado desde la comunidad}

Según las determinantes que se encontraron en el recorrido del Tour del Grafiti Comuna 13, de la ciudad de Medellín, podríamos determinar que los indicadores epistemológicos para que se gestione dicho itinerario como patrimonio cultural están expuestos de forma evidente y tangible, ya que la construcción de una proyección de reflexión comunitaria es la base argumentativa de cualquier iniciativa cultural para poner en consideración el mérito de salvamento y protección.

Bajo este esquema, podríamos precisar algunas de las consideraciones que, a juicio del grupo que realizó dicho estudio, dieron la relevancia argumentativa para la declaratoria de patrimonio cultural del hecho:

1. La Comuna 13 se apropia de las intervenciones de grafiti en sus fachadas y sus espacios públicos considerando que es una tradición
Vigura 5. Business Mode Canvas el Tour del Grafiti. Fuente: elaboración propia (2021)

\section{LIENZO DE MODELO DE NEGOCIO}

\begin{tabular}{|c|c|c|c|c|c|}
\hline \multirow{2}{*}{$\begin{array}{l}\text { Socios clave } \\
\text { - Artistas urbanos } \\
\text { - Administraciones } \\
\text { públicas (locales, } \\
\text { regionales y nacionales). } \\
\text { - Emprendedores locales } \\
\text { (Casa Kolacho, Centro } \\
\text { Cultural del Café con } \\
\text { Aroma de barrio, } \\
\text { Cremas doña consuelo, } \\
\text { entre otros). }\end{array}$} & $\begin{array}{l}\text { Actividades clave } \\
\text { - Reconocimiento de los } \\
\text { elementos patrimoniales } \\
\text { de la Comuna Trece. } \\
\text { - Promoción de los } \\
\text { atractivos turísticos } \\
\text { (eventos patrimoniales } \\
\text { - Planificación del } \\
\text { recorrido. }\end{array}$ & \multirow{2}{*}{\multicolumn{2}{|c|}{$\begin{array}{l}\text { Propuesta de valor } \\
\text { - Ofrecer una experiencia } \\
\text { histórico-cultural a } \\
\text { través de la presentación } \\
\text { de narrativas artísticas } \\
\text { de los habitantes de la } \\
\text { Comuna Trece }\end{array}$}} & \multirow[t]{2}{*}{$\begin{array}{l}\text { Relación con el cliente } \\
\text { - Asistencia personal; los } \\
\text { turistas reciben asesoría } \\
\text { de un guía a lo largo del } \\
\text { recorrido. }\end{array}$} & \multirow{2}{*}{$\begin{array}{l}\text { Segmentos de cliente } \\
\text { - Turistas nacionales } \\
\text { e internacionales } \\
\text { interesados en vivir } \\
\text { nuevas experiencias } \\
\text { culturales. }\end{array}$} \\
\hline & $\begin{array}{l}\text { Recursos clave } \\
\text { - Recursos físicos: } \\
\text { pictogramas } \\
\text { - Recursos humanos: guías } \\
\text { promotores } \\
\text { - Recursos intelectuales: } \\
\text { conocimiento histórico y } \\
\text { cultural } \\
\text { - Recursos económicos: } \\
\text { creación de actividades } \\
\text { artísticas. }\end{array}$ & & & & \\
\hline - Canales propios directos & $\begin{array}{l}\text { Ictura de costos } \\
\text { Jágina web y equipo de vent }\end{array}$ & as directo & $\begin{array}{l}\text { - Venta de a } \\
\text { - cuota por }\end{array}$ & $\begin{array}{l}\text { Fuentes de ingr } \\
\text { tivos: compras en emprendi } \\
\text { so: pago por el servicio de a }\end{array}$ & $\begin{array}{l}\text { esos } \\
\text { nientos locales. } \\
\text { ompañamiento en el tour }\end{array}$ \\
\hline
\end{tabular}


urbana que identifica de manera particular el asentamiento.

2. La Comuna 13 reconoce y destaca que a partir de haberse instaurado el tour de grafitis se reconstruyeron los vínculos barriales con el resto de la ciudad, lo cual dio alternativas de reconciliación y estrategias para la recuperación de la comuna.

3. La comunidad comprende que, como estrategia de reinvención, las intervenciones realizadas por los artistas y el deseo de otros de plasmar en los distintos barrios sus murales con mensajes alusivos a la historia del lugar, son un reconocimiento al esfuerzo que desde la participación comunitaria han logrado los distintos actores que han construido dicha toma.
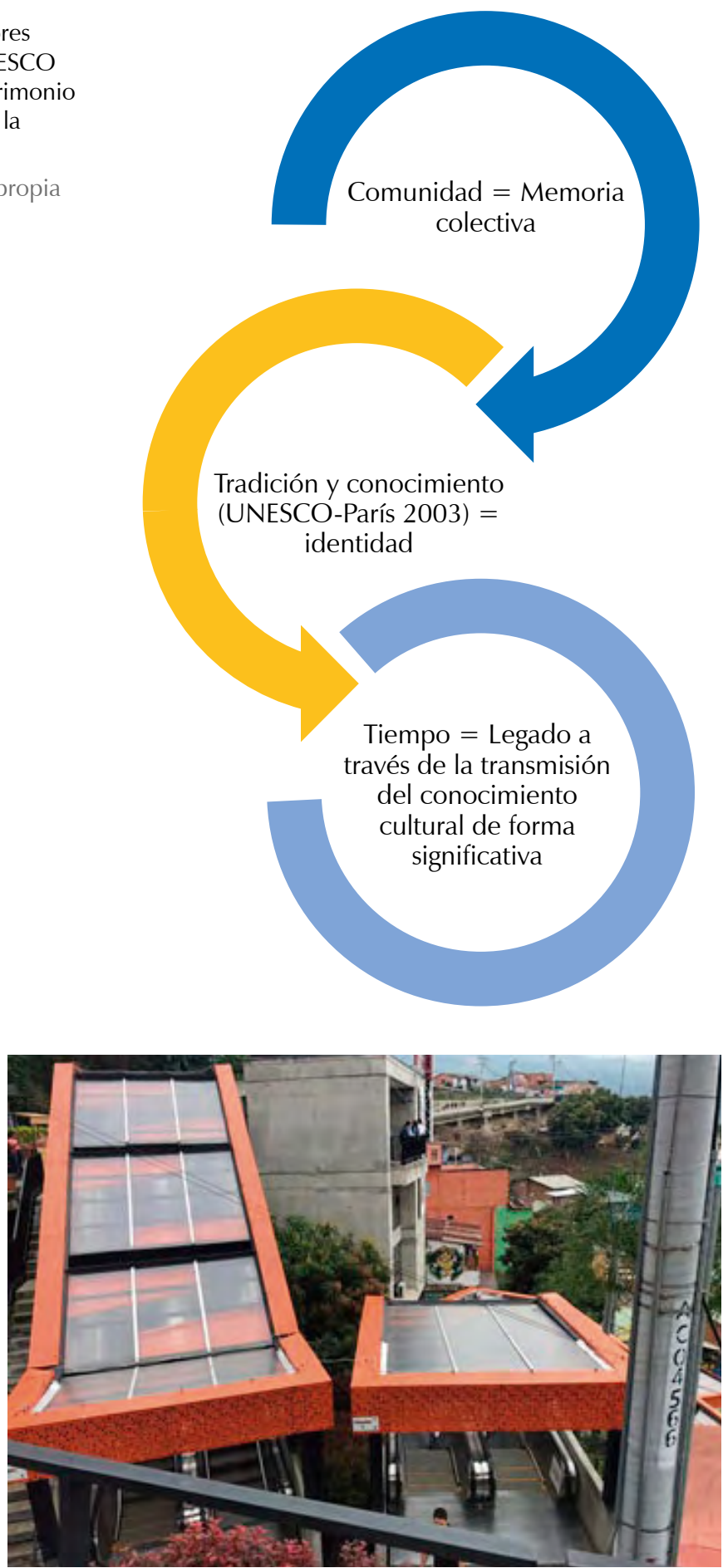

Aigura 6. Indicadores para el cotejo de patrimonio cultural de grafitis en la Comuna 13.

Fuente: elaboración propia (2019).
4. La comunidad considera que la transmisión de la memoria colectiva de una técnica pictórica a otras generaciones concreta las dinámicas propias de patrimonio cultural, ya que apoyan un fortalecimiento de la cultura a través del nacimiento de escuelas de arte de aprendizaje significativo para la población infantil y juvenil del sector.

5. La comunidad estructura como red de apoyo las intervenciones que fortalezcan el recorrido brindando seguridad y protección a todos los eventos que constituyen el Tour del Grafiti de la Comuna 13.

6. La Comuna 13 reconoce que el paisaje ofrecido por dichas intervenciones, respaldado por un reconocimiento institucional, podría ofrecer sostenibilidad al sistema de la comuna en la cocreación de proyectos que implican el mejoramiento de esta.

7. El modelo planteado en la Comuna 13 se entiende bajo la lógica del emprendimiento social, puesto que cumple con todas las premisas de un proyecto de esta naturaleza.

Si bien se reconoce que, como estrategia pública a un reconocimiento del fenómeno, se están realizando recorridos similares en distintas ciudades alrededor del mundo, y que este tour no es una única muestra de la práctica con cierto valor estético, sí se lo debe diferenciar de otras intervenciones de este tipo, al ser un evento de apropiación y gestión comunitaria como parte del proceso de reconstrucción de la comunidad misma. El Tour del Grafiti de la Comuna 13 relata, en cada una de las paredes de los barrios, una historia de abandono estatal que con el trabajo de sus líderes comunitarios llamaron la atención de las entidades gubernamentales y dieron la fuerza inspiradora a los diferentes actores para potenciar y revitalizar este sector dando paso a elementos que construyen dinámicas urbanas que trascienden límites y multiplican acciones de recuperación tanto paisajística como de recuperación económica.
A Figura 7. Escaleras eléctricas.

Fuente: fotografía de José Fernando Salazar Serna (2019).

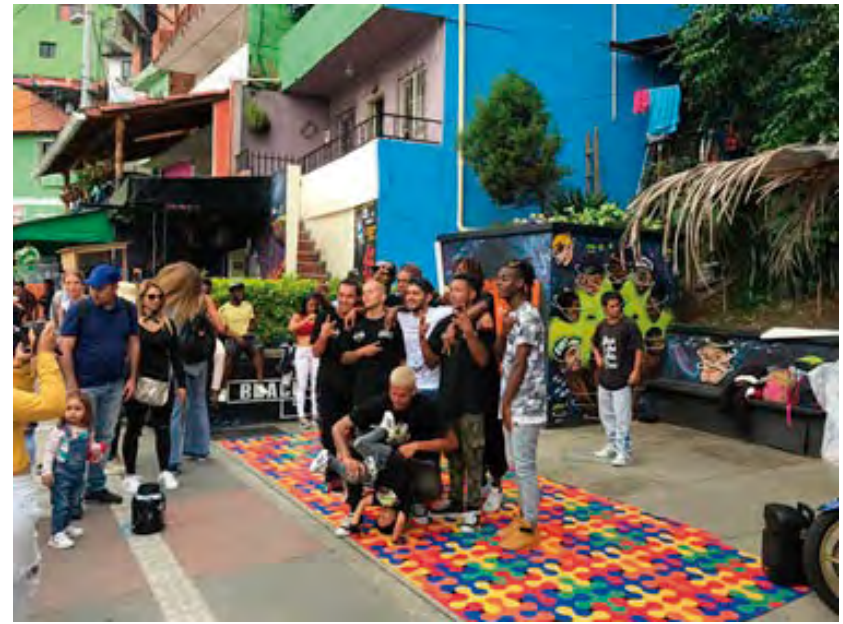

(A) Figura 8. Grupo de Danza de Hip Hop. Fuente: fotografía de José Fernando Salazar Serna (2019). 
También se debe recalcar que la reinvención de este paisaje urbano popular es, quizá, una potencialidad de la ciudad de Medellín, y que, por lo tanto, debido al creciente turismo en el sector, se hace imperativo tener una declaración y una salvaguardia como patrimonio cultural, para poder ser protegida de un turismo que depreda e incita a otras dinámicas que no favorecen el gran logro de recuperación de la comuna.

\section{Conclusión}

\section{Validación y capitalización del estudio de caso para el diseño de herramientas pedagógicas}

Si bien es cierto que una de las características del patrimonio cultural es que se trata de una actividad única y específica que interpreta la culturalidad de una comunidad, también es cierto que este ejemplo, por más particular que sea de la ciudad de Medellín, dio pauta al grupo del semillero para el desarrollo de dinámicas pedagógicas que permitieron capitalizar dicha experiencia en posibles actividades de aprendizaje para escenarios urbanos con contextos similares. La herramienta diseñada, basada en la técnica pedagógica de herramientas de mnemotecnia de aprendizaje activo, da el andamiaje por parte del poseedor de un saber académico para realizar la trazabilidad con el saber popular teniendo una plataforma reconocible para el desarrollo y la cocreación de un proyecto potenciador de dinámicas culturales. Objetivos como la identificación, la comunicación, la interpretación y la socialización se consideraron fundamentales, ya que permitieron a los participantes del ejercicio examinar con detalle el caso de la Comuna 13 para explorar dinámicas pedagógicas de acercamiento social a través del juego, para reconocer y dar luces, para que, en la creación de nuevos proyectos de manera conjunta "comunidad y academia", persigan objetivos de similares características. La identificación de actividades, recursos y actores brinda la posibilidad de replicar este modelo exitoso en otras latitudes y abre camino para continuar con el debate de la resignificación de la ciudad que reconoce la diversidad como principio de su crecimiento y de su desarrollo natural, como lo afirman acerca de los grafitis en la ciudad Gama-Castro, M. y León-Reyes:

\begin{abstract}
Narran en las paredes de los altos edificios historias de amor, sucesos del conflicto armado, costumbres, crítica social, posturas políticas; que decidieron, a través del arte, hacer memoria y ahora son pocas las calles que no tienen un dibujo, una historia, un pensamiento, una postura, una idea. (Gama-Castro \& León-Reyes, 2016, p. 357)
\end{abstract}

\section{Referencias}

Beddall, L. (2017). Colombian artists muscle out crime: Artistic youth transform Medellin district, which was once the most dangerous area in south America, through community initiative. Toronto Star.

https: //www.thestar.com/life/ travel/2017/04/13/change-gains-momentumin-medellin.html

Carretto, M., Harispe, M., \& Vaz, F. (2013). Refresher: The Business Model Canvas: un lenguaje común para describir, visualizar, evaluar y cambiar modelos de negocios. Taller Encararé, 46.

http://www.fadu.edu.uy/marketing/ files/2013/04/BMC_2015.pdf

Gama-Castro, M., \& León-Reyes, F. (2016). Bogotá arte urbano o graffiti. Entre la ilegalidad y la forma artística de expresión. Arte, Individuo y Sociedad, 28(2), 355-369. https://doi.org/10.5209/rev ARIS.2016.v28. n2.49933

https://www.mincit.gov.co/getattachment/ estudios-economicos/estadisticas-einformes/informes-de-turismo/2018/oee-vtturismo-2018-28-03-2019.pdf.aspx

Klein, R. (2018). La ciudad y el turismo. Experiencias desde la gestión del street art. Sociologia: Revista da Faculdade de Letras da Universidade do Porto. Temático, 54- 71. http://dx.doi.org/10.21747/08723419/ soctem2018a3

Ministerio de Comercio, Industria y Turismo. (2018). Resultados para el turismo para el año 2018. Migración Colombia.
Montalvo-Castro, J. (2016). Emprendimientos digitales y diseño de modelos de negocio: investigación aplicada en estudiantes de la Carrera de Comunicación. Contratexto, 0(25), 155-170.

https://doi.org/10.26439/contratexto2016. n025.656

Mora Castiblanco, J. E. (2014). La transposición didáctica del saber sabio al saber enseñado. Autor: Yves Chevallard. Góndola, enseñanza y aprendizaje de las ciencias, 9(2), 97-100. https://doi.org/10.14483/jour. gdla.2014.2.a07

Osterwalder, A., \& Pigneur, Y. (2011). Generación de modelos de negocio. Un manual para visionarios, revolucionarios y retadores. Journal of Product Innovation Management, 13(2), 180-181.

https://cecma.com.ar/wp-content/ uploads/2019/04/generacion-de-modelosde-negocio.pdf

Ramírez Bravo, R. (2005). Aproximación al concepto de transposición didáctica. Revista Folios, (21),33-45.

https://www.redalyc.org/articulo. oa?id=345955978004

Reyes Sánchez, F. (2012). Graffiti. ¿Arte o vandalismo? Pensar La Publicidad. Revista Internacional de Investigaciones Publicitarias, 6, 53-70.

https://doi.org/10.5209/rev_PEPU.2012. v6.40636

Rojas de Francisco, L., \& Henao, D. (2017). Casa Kolacho: Participación ciudadana y narrati- vas transmedia en la comuna 13 de Medellín-Colombia. En A. Cabral, C. Bolaño, D. Araujo, F. Andacht, \& F. Paulino (Eds.), Nuevos conceptos y territorios en América Latina. Comunicación audiovisual literatura $y$ artes (pp. 564-580). EAFIT.

UNESCO. (1982). Declaración de México sobre las políticas culturales, Conferencia mundial sobre políticas culturales México D.F. https://unesdoc.unesco.org/ark:/48223/ pf0000052505_spa

UNESCO. (2000). Foro Mundial sobre la Educación. Marco de acción Dakar-Educación para todos: cumplir nuestros compromisos comunes. Adoptado en el Foro Mundial sobre la Educación.

https://siteal.iiep.unesco.org/ investigacion/3192/marco-accion-dakareducacion-todos-cumplir-nuestroscompromisos-comunes

UNESCO. (2002). Hábleme del Patrimonio Mundial.

https:/docplayer.es/22181639-Patrimoniomundial-ediciones-unesco.html

UNESCO. (2003). Convención para la salvaguardia del patrimonio cultural inmaterial 32 a reunión.

https://unesdoc.unesco.org/ark:/48223/ pf0000132540_spa

Vázquez Parra, J. C. (2018). Elementos para la valoración integral de proyectos de emprendimiento social. Una herramienta para la formación de emprendedores. Contabilidad y Negocios, 13(26), 129-140.

https://doi.org/10.18800/contabilidad.201802.008 

(1) Portada: Las bovedadas de Bramante.

Fotografía: Luis Alberto Martínez Camacho (2021) CC BY-NC

\section{(ब) (1) (\$)}

(A) Orientación editorial

\section{Enfoque y alcance}

La Revista de Arquitectura (Bogotá) ( (ISSN 1657-0308 Impresa y E-ISSN 2357-626X en línea) es una publicación científica seriada de acceso abierto, arbitrada mediante revisión por pares (doble ciego) e indexada, en donde se publican resultados de investigación originales e inéditos.

Está dirigida a la comunidad académica y profesional de las áreas afines a la disciplina. Es editada por la Facultad de Diseño y el Centro de Investigaciones (CIFAR) de la Universidad Católica de Colombia en Bogotá (Colombia).

La principal área científica a la que se adscribe la Revista de Arquitectura (Bogotá) según la OCDE es:

Gran área: 6. Humanidades

Área: 6.D. Arte

Disciplina: 6D07. Arquitectura y Urbanismo

También se publican artículos de las disciplinas como 2A02, Ingeniería arquitectónica; 5C03, Estudios urbanos (planificación y desarrollo); 6D07, Diseño.

Los objetivos de la Revista de Arquitectura (Bogotá) son:

- Promover la divulgación y difusión del conocimiento generado a nivel local, nacional e internacional

- Conformar un espacio para la construcción de comunidades académicas y la discusión en torno a las secciones definidas.

- Fomentar la diversidad institucional y geográfica de los autores que participan en la publicación.

- Potenciar la discusión de experiencias e intercambios científicos entre investigadores y profesionales.

- Contribuir a la visión integral de la arquitectura, por medio de la concurrencia y articulación de las secciones mediante la publicación de artículos de calidad.

- Publicar artículos originales e inéditos que han pasado por revisión de pares, para asegurar que se cumplen las normas éticas, de calidad, validez científica, editorial e investigativa.

- Fomentar la divulgación de las investigaciones y actividades desarrolladas en la Universidad Católica de Colombia.
Palabras clave de la Revista de Arquitectura (Bogotá): arquitectura, diseño, educación arquitectónica, proyecto y construcción, urbanismo.

Idiomas de publicación: español, inglés, portugués y francés. Título abreviado: Rev. Arquit.

Titulo corto: RevArq

\section{Políticas de sección}

La revista se estructura en tres secciones correspondientes a las líneas de investigación activas y aprobadas por la institución, y dos complementarias, que presentan dinámicas propias de la Facultad de Diseño y las publicaciones relacionadas con la disciplina.

Cultura y espacio urbano. En esta sección se publican los artículos que se refieren a fenómenos sociales en relación con el espacio urbano, atendiendo aspectos de la historia, el patrimonio cultural y físico, y la estructura formal de las ciudades y el territorio.

Proyecto arquitectónico y urbano. En esta sección se presentan artículos sobre el concepto de proyecto, entendido como elemento que define y orienta las condiciones proyectuales que devienen en los hechos arquitectónicos o urbanos, y la forma como estos se convierten en un proceso de investigación y nuevo de conocimiento. También se presentan proyectos que sean resultados de investigación, los cuales se validan por medio de la ejecución y transformación en obra construida del proceso investigativo. También se contempla la publicación de investigaciones relacionadas con la pedagogía y didáctica de la arquitectura, el urbanismo y el diseño.

Tecnología, medioambiente y sostenibilidad. En esta sección se presentan artículos acerca de sistemas estructurales, materiales y procesos constructivos, medioambiente y gestión, relacionados con los entornos social-cultural, ecológico y económico.

Desde la Facultad. En esta sección se publican artículos generados en la Facultad de Diseño, relacionados con las actividades de docencia, extensión, formación en investigación o internacionalización, las cuales son reflejo de la dinámica y de las actividades realizadas por docentes, estudiantes y egresados; esta sección no puede superar el $20 \%$ del contenido.

Textos. En esta sección se publican reseñas, traducciones y memorias de eventos relacionados con las publicaciones en Arquitectura y Urbanismo.
A Frecuencia de publicación

Desde 1999 y hasta el 2015, la Revista de Arquitectura (Bogotá) publicó un volumen al año, a partir del 2016 se publicarán dos números por año en periodo anticipado, enero-junio y julio-diciembre, pero también maneja la publicación anticipada en línea de los artículos aceptados (versión Post-print del autor).

La Revista de Arquitectura (Bogotá) se divulga mediante versiones digitales (PDF, HTML, EPUB, XML) e impresascon un tiraje de 700 ejemplares, los tiempos de producción de estas versiones dependerán de los cronogramas establecidos por la editorial.

Los tiempos de recepción-revisión-aceptación pueden tardar entre seis y doce meses dependiendo del flujo editorial de cada sección y del proceso de revisión y edición adelantado.

Con el usuario y contraseña asignados, los autores pueden ingresar a la plataforma de gestión editorial y verificar el estado de revisión, edición o publicación del artículo.
A Canje

La Revista de Arquitectura (Bogotá) está interesada en establecer canje con publicaciones académicas, profesionales o científicas del área de Arquitectura y Urbanismo, como medio de reconocimiento y discusión de la producción científica en el campo de acción de la publicación.

Mecanismo

Para establecer canje por favor descargar, diligenciar y enviar el formato: RevArq FP20 Canjes

Universidad Católica de Colombia (2021,
junio-diciembre). Revista de
Arquitectura (Bogotá), 23(2),
I-132. Doi: 10.14718
ISSN: I657-0308
E-ISSN: 2357-626X
Especificaciones:
Formato: $34 \times 24 \mathrm{~cm}$
Papel: Mate II5 g
Tintas: Negro y policromía

A Contacto

Dirección postal:

Avenida Caracas N ${ }^{0} \cdot 46-72$ Universidad Católica de Colombia Bogotá D. C., Colombia Código postal: 111311

Facultad de Diseño Centro de Investigaciones (CIFAR) Sede El Claustro. Bloque "L", 4 piso Diag. 46A N ${ }^{0 .} 15 b-10$ Editor, Arq. César Eligio-Triana

Teléfonos:

+57 (1) $3277300-3277333$

Ext. $3109 ; 3112$ o 5146
Fax: +57 (1) 2858895

Correo electrónico:

revistadearquitectura@ucatolica.edu.co cifar@ucatolica.edu.co

Página WEB:

www.ucatolica.edu.co

Vínculo Revistas científicas

http://publicaciones.ucatolica.edu.co revistas-cientificas

https://revistadearquitectura.ucatolica.edu.co/ 
